\title{
People Analytics and Performance of Deposit-Taking Micro Finance Institutions in Nyeri County, Kenya
}

\author{
Anne Wambui Muriithi ${ }^{1}$, Dr. Paul Waithaka ${ }^{2}$ \\ ${ }^{1}$ School of Business, Kenyatta University, Kenya \\ ${ }^{2}$ Department of Business Administration, School of Business, Kenyatta University
}

\begin{abstract}
People analytics is a data-driven approach to improving people-related decisions for advancing both individual and organizational success. While people have always been critical to the success of organizations, many business leaders still make key decisions about their workforce based on intuition, experience, advice, and guesswork. However, today leaders can improve their people decision-making based on the collection and systematic analysis of data. A closer look at the operations of many deposit taking micro-finance institutions reveals that they all face challenges related to human resources management. These firms invest in human development, only for the human capital to leave for greener pastures within a short period, impacting negatively and heavily on performance, survival and growth. It is therefore imperative that they undertake serious human resource evaluation, and people analytics can be a crucial tool for the success of this process. The aim of the study was thus to evaluate the effect of people analytics on the performance of Deposit Taking Micro Finance Institutions in Nyeri County, Kenya. The specific objectives guiding the study were: to determine the influence of technology adoption on the performance of deposit taking micro-finance institutions, effect of human resource data access on the performance of deposit taking micro-finance institutions, effect of data management capacity on the performance of deposit taking micro-finance institutions, and the effect of stewardship for people analytics on the performance of deposit taking micro-finance institutions in Nyeri County, Kenya. The study adopted the descriptive research design while targeting 173 respondents comprising 8 human resource managers and 165 staff in the human resource department of 8 registered deposit taking micro-finance institutions in Nyeri County. Through stratified sampling method, all managers (8) and $30 \%$ (50) of the 165 staff comprised the sample size of 58 respondents. The selected respondents were considered key informants in the study area. Data was collected from primary sources using a semistructured questionnaire. Data was analyzed with the aid of Statistical Package for Social Studies and excel computer software through descriptive (percentages, means, standard deviation), as well as inferential statistical methods (correlation and regression techniques). Tables and graphs were used for data presentation. Results showed that the micro finance institutions had established infrastructure for the application of technology. Descriptive and inferential analysis results indicated that technology adoption, human resource data access, data management and stewardship had a positive relationship with the performance of MFIs. Findings further indicated that out of the four independent variables, only three were significant: human resource data access, data management and stewardship. The study thus concluded that HR data access, data management and stewardship aspects of people analytics had significant effect on the performance of Microfinance Institutions. Technology adoption lowly affected people analytics and performance of micro finance institutions. To enhance data access and management, the study recommended that managers need to invest in new apps that are platforms for people analytics including cloud computing and artificial
\end{abstract}


intelligence. They must also re-evaluate the techniques for human resource anaytics as well as capacity development in people analytics for managers and staff.

Key Words: People Analytics, Human Resource Data Access, Data Management Capacity, Stewardship, Performance of Deposit-Taking Micro Finance Institutions

DOI: $10.35942 / \mathrm{ijcab} . v 3 i V .70$

\section{Cite this Article:}

Muriithi, A., \& Waithaka, P. (2019). People Analytics and Performance of Deposit-Taking Micro Finance Institutions in Nyeri County, Kenya. International Journal of Current Aspects, 3(V), 186-209. https://doi.org/10.35942/ijcab.v3iV.70

\section{Introduction}

Microfinance concept has gained a universal recognition in developing countries. The performance concept relating is a vital and crucial issue for ensuring donors and investors about effective and efficient utilization of funds injected in Micro Finance Institution (MFI) programs, also helping regulators to controlling and monitoring the MFIs. Ineffective MFIs represent a main constraint on the development of the microfinance industry and therefore, performance measurement is a crucial tool for managing MFIs and is a requirement for sustainability. Muogbo (2013) contended that assessing the performance of an MFI is about examining its development towards accomplishing goals. Impact assessment is promoted by both the sponsors and practitioners of programs so that they can understand what is being attained and improve the efficiency and effectiveness of their activities. Katua, Mukulu and Gachunga (2014) accorded that organizational performance comprises the actual output or results of an organization as measured against its intended outputs. It involves the ability of an organization to fulfill its mission through sound management, strong governance and a persistent rededication to achieving results.

Dauda, Akingbade, and Akinlabi (2010) contend that the high achieving firms have continued to align their human resource strategies with the changing business environment despite the influence of competition, globalization, technology, consumer demands, costs of operation, workforce diversity are among the drivers of organizational change. However though, performance of organizations in the global business environment is determined by internal and external factors that influence human resource capacity, (Ghazala \& Habib, 2012). According to Campero (2016), people analytics revolution is gaining traction globally. This is evident in that as Human Resource (HR) institutions are contemplating building analytics teams for several years, in the year 2016 there has been a major leap forward in capabilities. Organizations and most especially businesses have recognized the importance of data in configuring what makes people join, perform well in, and stay with an organization; the persons who will likely be successful; the persons to make the best leaders; and what is required to deliver the highest-quality customer service and innovation. All of these can be directly informed by people analytics. In regards to human resources decisions, organizations - including the deposit-taking Micro Finance Institutions (MFIs) - want to make sure they are putting the right people in the right places so that they contribute optimally to the success of the overall enterprise with maximum efficiency (Sparrow, Hird \& Cooper, 2015).

Increasingly, people analytics are being used to achieve this objective. Now, organizations engaging hiring people analytics professionals, cleaning up their data, and developing models that help transform their businesses (Thomas, Jeanne \& Jeremy, 2010). Currently, analytics technology is available off the shelf, embedded in most Enterprise Resource Planning (ERP) and Talent Management Systems (TMS), recruitment and learning platforms engagement 
tools, text and semantic analysis tools. According to Ben (2013), people analytics today brings together HR and business data from different parts of the business and is now addressing a wide range of challenges including analyzing flight risk, selecting highperforming job applicants, identifying characteristics of high-performing sales and service teams and predicting compliance risks. It also entails analyzing engagement, culture, identifying high-value career paths and leadership candidates. Globally, retail banks, manufacturing firms as well as software companies are evaluating characteristics of top salespersons, realizing that their personal networks, how they work internally, and the time they spend with customers predict results much more accurately than the amount of sales training or experience (Laumer, Eckhardt, \& Weitzel, 2010). Josh (2014) indicated that Google uses analytics to gain insights into the impact of every interview and source of hire. According to Collins and Bernnett (2015), many companies, including Pfizer, AOL, and Facebook, now analyze the factors that correlate with high-performer retention. As an example, British Petroleum Company uses analytics to evaluate its training. SAB Miller uses analytics to drive high quality standards across a variety of programs worldwide.

Data held in Human Resource Information Systems (HRIS) typically comprises of information on the workers who are hired (employment history, skills and competencies, formal educational qualifications, demographic information) and on those applicants that were not hired. Once the worker is employed, data on working hours and pay is collected and stored routinely. Depending on the job role, there may also be information on the performance of workers (sales made, hours billed to clients, measures of individual output etc.). According to Ulrich (2015), leverage analytics skills outside HR are crucial for the success of people analytics by enlisting the support of Information Technology (IT), marketing analytics, and other analytics teams in the company. Parry (2011) accorded that to enhance data management, companies should explore new technologies. Aral and Wu (2012) finding contended that, capacity building, managing, motivating, and developing a HR team to effectively carry out the MFI's mission can be enhanced through HRM tools and systems. By building strong, well-functioning human resource systems and tools, MFIs will be poised for growth, ready to manage the challenges of an evolving environment, and responsive to the needs of clients. CAHRS (2014) advocate that with statistical methods and big data usage entrenched in nearly all other facets of business - from predicting supply and output in supply chain, to predicting a range of financial outcomes in finance, to using mass swaths of information for predicting customer preferences in marketing - HR has been slower to embrace its usage in practice. Research has shown that few organizations are actively implementing people analytics capabilities to address complex business and talent needs (Collins \& Bernnett, 2015). According to Harvard Business Review survey (2015) of executives - one-third being HR professionals themselves, the biggest obstacle to achieving better use of data and people analytics was inaccurate, inconsistent, or hard-to-access data requiring too much manual manipulation. Actually, $47 \%$ of the participants cited that the biggest obstacle was a lack of analytic acumen or skills among HR professionals.

\subsection{People Analytics}

Boudreau and Lawler (2015) contend that the rise in complexity of workforce challenges correlates positively to demand for more quantitative approaches to address the increasingly difficult people-related questions central to organizational success. According to Collins and Bernnett (2015), people analytics are a set of analytics that starts with a talent-management business question- such as who should the firm attract, acquire, develop, promote or retainand integrates internal and external talent data (referring to publicly available data, company data, and labor market data) to make a prediction about workforce behaviors and actions across the organization, and enables the tracking of the results. They posit that people 
analytics encompasses usage of data-driven approach to inform an organization's people practices, programs and processes. Rasmussen and Ulrich (2015) contended that analytical techniques, ranging from reporting and metrics to predictive analytics to experimental research can help a firm uncover new insights, solve people problems and direct the firm's HR actions. Sparrow, Hird and Cooper (2015) posited that the power of people analytics is in its ability to challenge conventional wisdom, influence behavior, enable talent and business leaders to make and execute smarter and more strategic workforce decisions, and ultimately impact business outcomes. Advanced analytics provides a unique opportunity for humancapital and human-resources professionals to position themselves as fact-based strategic partners of the executive board, using state-of-the-art techniques to recruit and retain the great managers and great innovators who so often drive superior value in companies.

George, Haas and Pentland (2014) contended that today's people analytics teams bring together data from a range of sources, including core HR systems, employee engagement data, survey data, external data and text data from employee comments. They then analyze these data to understand the firm's culture, identify opportunities to improve retention or performance, or diagnose management weaknesses or other operational problems. Kaufman (2014) further contended that HR teams should learn about new analytics vendors to find the right tapestry of technologies. It is also important to invest in cleaning data. They argued that the highest value in analytics comes after the company runs an integrated, valid, and reliable database; efforts that may take time and involve IT, but pay off. Bersin (2015) posited that analytics normally falls into one of three categories: descriptive (what happened), predictive (what could happen), and prescriptive (what should happen). Utilization of these interwoven statistical approaches helps to clarify historical trends, find correlations and patterns among variables, look into the future, mitigate legal risk, and maintain objective decision-making. According to Cascio and Boudreau (2014), companies now engage industrial and organizational psychologists, statisticians, and analysts from other domains into HR; having been attracted to analytics because it is an exciting, new, and still-fluid area. Thus, companies are recruiting the right talent and/or integrate disparate analytics efforts- employee engagement, recruitment analytics, learning analytics, compensation analytics, and workforce planning (Rasmussen \& Ulrich, 2015). This is a key ingredient of successful analytics projects. People analytics engages the use of technology in analyzing the workforce. The investment in Information and Communication Technologies (ICT) by companies contributes to the effectiveness of people analytics as it provides means for data collection, configuration and storage. The stored data may then be used to analyses individual capacities that inform HR decisions. According to Michael, David and Robin (2017), analytics is the discipline which has developed at the intersection of engineering, computer science, decision making and quantitative methods to organize, analyze and make sense of the increasing amounts of data being generated by contemporary societies (Mortensen, Doherty \& Robinson, 2015).

Douthit and Mondore (2014) noted that the rapid development of science and technology which is now fundamentally changing people's lifestyle and social modes of production brings more complex and rapidly changing social environments and economic environments as well as more intense competition. As such, organizations should depend both on developments of physical product and on good and fast service delivery to remain relevant in the market competition. However, Ulrich (2015) contended that the HR function is lagging behind other functional areas of management in the adoption of analytics technology and in the analysis of big data. Contrary to optimistic accounts from industry sources, there is little evidence that HR analytics is developing into a 'must have capability' which will ensure HR's future as a strategic management function. A lack of technology, system integration, and enterprise-wide visibility may have tarnished HR's credibility enough to stymie internal 
acceptance of a more data-driven approach. Many in the HR profession do not understand analytics or big data, while analytics teams do not understand HR. As a result, the costly analytics capabilities provided by the latest forms of HRIS are failing to deliver strategic HR analytics capabilities (Ulrich \& Dulebohn, 2015). But overcoming these legacy issues and embracing big data can allow HR to analyze structured and unstructured data to help answer important questions regarding people and operations. Embracing cloud technology overcomes many IT problems that can beset HR and allows access to talent analytics. Cloudbased tools are faster to implement, requiring fewer IT resources and multiple tools can often be linked into one integrated system. The technical means to integrate, organize and analyze data held in conventional HRIS with data from other larger unstructured sources (blogs) are yet not well established. There are also significant issues of privacy, consent and ethics to address when storing and analyzing HR data. Smeyers (2015) noted that related to this, insufficient data to ask the right questions may be a constraint. Further, silo mentalities within organizations prevent HR related data being combined with data on other determinants of productivity and performance, so it is often hard to build analytical models that examine the role of HR related factors while controlling for other relevant factors. These weaknesses in the HR profession are compounded by the analytics industry itself.

According to Huselid (2015), incredible business value is contained in the data an organization creates and preserves. Daily, HR professionals are tasked with accessing these silos of information to perform their duties, which equates to the frustrating task of working from systems that are non-integrated, poorly integrated, or have multiple interfaces. Challenges experienced by HR professionals include rekeying existing data, inconsistent and duplicate data and/or systems, coping with various data formats, and decreased response times for requests. Campero (2016) indicated that as the needs and complexity of the business grow, the challenges inherent in the demand for data access continue to increase. Without a means for the HR organization to easily and quickly leverage data from systems and applications, these professionals struggle to generate positive results. According to Felin, Foss and Ployhart (2015), data management is a significant advantage of implementing cloud-based benefits management. Cloud-based platforms are able to centralize multiple data sources so that HR professionals can leverage employee data, using it to create more benefits or address unspoken issues. With the influx of wearables in the workplace, companies are now able to obtain tremendous amounts of data and use that information to monitor and improve employee productivity, as well as reduce health care costs. Organizing and then using intelligently the large amount of data that exists in this digital era can help businesses gain a competitive advantage.

Foss and Pedersen (2014) contended that business intelligence tools and new-generation technology have moved from heavily-discussed trends to real solutions that help businesses translate huge amounts of data in actionable insights that drive performance. The correct implementation of the right analytics tools at the right time provides assurance that an organization has multiplied its chances of having high-potential resources matched to the right job today, as well as in the future. Kassim and Nagy (2015) posited that by using an analytical approach to assess team fit and job match throughout each employee's employment life cycle, a business can build an agile workforce that is consistently capable of high-value execution. According to Collins and Bernnett (2015), quality of data in HR continues to be a challenge. New cloud HR technology helps tremendously the problem requires a systemic solution. To promote people analytics, organizations need to evaluate data quality at all levels, put in place privacy and anonymity policies, and carefully implement practices to secure employee data from theft and abuse. Advanced companies now have governance 
teams that make sure all people-related data are coordinated as the company reorganizes, acquire others, and implements new systems.

Davenport (2013) contended that leadership development in organizations is a critical strategic initiative. HR managers are expected to provide the essential structures, processes, tools, and points of view to make the best selection and develop the future leaders of the organization. The World Federation of Personnel Management Associations (WFPMA) reports that across the globe leadership development has been identified as a critical strategic initiative in ensuring that the right employees are retained, that the culture of the organization supports performance from within to gain market position, and that managers are equipped to take on leadership roles of the future so that the organization is viable in the long term. Stewardship in people analytics is pivotal in HR development strategies. Management and supervisory staff play an important role in formulating strategies and principles for employee data access and appraisal methods. The role of a manager has always been demanding and ever evolving. Managers enable their team members to achieve their goals, maintain high levels of productivity, and ensure a focused and aligned effort. Multiple responsibilities and continually changing workplace trends make the work of a manager more challenging than that of an employee working for the manager (Evans, Pucik, \& Björkman, 2011). Along with managing a wide variety of tasks, managers are expected to also put in efforts for speedy decision-making, time management and strategic thinking. Mercer (2012) argued that absence of a well-structured appraisal process leads to ineffective performance evaluation. Further, lack of managers' feedback and inability to make appraisal meetings meaningful in the organization results in low employee performance.

\subsection{Organizational Performance}

According to Stevenson (2004), performance is the outcome of an individual or group contribution of development in any activity leading to results (positive / negative). It comprises actual outputs or results of an organization as a matrix for intended goals and objectives. According to Upadhaya, Munir and Blount (2014) organizational performance encompasses three specific areas of firm outcomes: financial performance (profits, return on assets, return on investment); product market performance (sales, market share); and shareholder return (total shareholder return, economic value added). Hence, Organizational performance is the ability of an organization to fulfill its mission through sound management, strong governance and a persistent rededication to achieving results. Khan (2010) proposed that organizations delivering services need to broaden their examination of productivity from the conventional company-oriented perspective to a dual company-customer perspective. This enhances conflicts resolution or leverage synergies between improving service quality and boosting service productivity. Organizations adopting best practices are able to deliver their products and services. When defining Organizational performance, it is important to consider a wide variety of potential organizational performance measures. However, this research considered organizational performance relative to the workforce capacities analytics in the DTMs. Companies can achieve the dual-result of leveraging employees' insights and creating buy-in for data-driven decisions by incorporating their employees in the analytics process. Coco, Jamison and Black (2011) provide a detailed case study of how the home improvement retail chain, Lowes, used HR Analytics to establish a link between HR processes, employee engagement, and store performance. Through use of HR Analytics, Lowes was able to establish that highly engaged employees lead to $4 \%$ higher average customer ticket sales per store. Companies can solicit ideas from employees for business problems to analyze. They can further reward the employees who submitted a business case that eventually gets analyzed and intervened with. The Chartered Institute of Personnel and 
Development (CIPD) (2013) contended that regarding analytics and performance management, companies can invite employees to suggest traits in managers that they value.

Douthit and Mondore (2014) contended that data-driven decision-making follows from careful empirical analysis using advanced statistical and econometric techniques that move beyond the analysis of correlation between variables to use experiments and quasiexperiments to identify how human capital inputs affect the performance of the organization. Changes follow when analytics show that a particular policy or approach enhances performance, and that there is a significant return on improved performance. Analytics capabilities can thereby be focused on optimizing the performance of key talent segments and ensuring that the organization can adequately resource the talent it needs in the future (Boudreau \& Jesuthanan, 2011; Cascio \& Boudreau, 2014). The WFPMA reported that where HR departments have traditionally focused on measuring their own effectiveness, there is an evolving recognition that they can provide organizational value by measuring the effectiveness of the entire business organization. The shift is significant as it represents movement from simply counting the numbers hired to determining the Return on Investment (ROI) of collective and individual hires on a long-term basis.

\subsection{Micro Finance Institutions}

The microfinance industry in Kenya is now recognized to significantly enable financial inclusion for the financially underserved and unserved in the formal financial ecosystem. The MFIs have consistently added value to customers' livelihood through partnerships with various stakeholders like investors, banks, other financial institutions, credit bureaus, NGOs and other emerging agencies (Romano, Chege, Mutua \& Musiega, 2014). Angrave and Stuart, et al. (2016) indicate that the MFI sector has seen a paradigm shift in the last few decades though it is currently very complex and involves scores of MFIs and microfinance investment vehicles, which is a staggering shift from its inception as microcredit offered to customers with zero banking access across the world. The sector has addressed the financial inclusion agenda in most developing countries like Kenya. However, the MFI growth challenges abound and revolve around higher cost of funds, increase in risks due to geographical concentration, increase in cash carrying costs, unavailability of quality technology solutions, and rise in cases of fraud and high churn in human capital employed by these institutions (Angrave, et. al., 2016). Fink (2010) contended that poaching of resources by the larger MFIs from mid-and small-sized MFIs is one of the biggest challenges in the industry. Access to low-cost capital and funds, coupled with balance sheet size for Mid and small MFIs, the larger MFIs are able to offer enhanced compensation to employees from mid-and small sized MFIs, increasing attrition at these institutions.

MFIs also incur-apart from costs incurred in recruitment- substantial training costs due to the lack of sector-specific training courses in educational institutions. Further, identification of talented personnel within the organisation is a challenge faced by industry players as the sector has been scaling up only recently (Fink, 2010). While the core values, vision, mission and code of conduct form the basis of organisational culture in MFIs, the senior management of the organisation heavily influences them, rather that appraisal and analytical reports. Institutionalising this culture through professional HR and operational practices remains an unaddressed challenge.

\subsection{Deposit Taking Micro Finance Institutions in Kenya}

Deposit-taking Microfinance institutions (DTMs) in Kenya are currently facing competitive business environment caused by the current trends by established financial institutions such as banks, offering financial services customized for the low-income earners, a niche that had 
been previously dominated by the MFIs (Helmut, 2011). In a bid to remain competitive in such markets, DTMs have been forced to ensure that they implement appropriate HRM practices to retain their employees and remain competitive. This study sought to establish the HRM practices adopted by Deposit-taking MFIs and their effect on retention of employees. The Kenyan microfinance sector began in the late 1960s with a few NGOs that set up pilot programs providing donor funded credit services. According to Association of Microfinance Institutions (AMFI, 2014) there are 49 formal Microfinance institutions (MFIs) with 13 Regulated as Deposit taking MFIs (DTMS), 5 banks offering microfinance services, 4 Wholesalers advancing loans to other MFIs, 1 SACCO, 1 Development organization and 29 Retail lenders. According to CBK website two more DTMs were license early this year bringing up the number of DTMs to 11 (www.cbk.co.ke). The exact number of the informal MFIs is however hard to determine due to its diversity and complete regulation platform which includes all Microfinance service providers. All these groups came in to bridge the gap created by mainstream banks.

Currently, they serve over 6.5 million clientele according to the AMFI (2015). Their success stories and contributions to both social and economic factors have made the industry become an icon in the country hence many parties have drawn their focus to it. DTMs in Kenya have faced several constraints and challenges with stiff competition in the sector being the most current. Some of the major challenges to the development of microfinance business in Kenya include lack of specific legislation and set of regulations to guide the operations and insufficient use of human resource management practices since the industry is labour intensive. The task and challenge for human resource management practitioners is to introduce innovative techniques that help managers within an organization to articulate clear goals that can be understood and undertaken by a workforce (Romano, 2014).

\section{Statement of the Problem}

The microfinance industry has traversed a long path in its growth from being barely an additional mode of raising finances for the rural and semi-urban people in Kenya to becoming a direct means of helping them run their day-to-day business (AMFI, 2014). The industry has been a saviour to millions of people in the remote areas of the country and provided them with a glimmer of hope by empowering them with the means to fulfil their dreams. The sector has now started to attract significant domestic as well as foreign investments over the last few years, (Romano, 2014). Driven by competitive pressures and the greater availability of more integrated systems, organizations are aggressively building people analytics teams. The success of analytics comes down to measuring the value of people to organization and analytics is key to unlocking that value (Angrave, Charlwood, Kirkpatrick, Lawrence \& Stuart, 2016). Companies were investing heavily in HR systems replacement projects and talking about analytics, but few were actually making progress in this vital new business function. There is much room for improvement (Cascio \& Boudreau, 2014). A closer look at the operations of many DTMs reveals that they all face challenges related to human resources management. First and foremost, these institutions are labor-intensive since they offer services that are highly personalized and relational in nature. Lack of clear training and development programs as well as leadership that is not wholly committed to employee welfare, are some of the challenges that have dogged effective strategic human resource management practices in DTMs (Helmut, 2011).

Notably, the MFIs invest in human development, only for the human capital to leave the organization for greener pastures within a short period. The economic loss to such firms impacts negatively and heavily on their performance, survival and growth, (Cascio \& Boudreau, 2014). It is therefore imperative that the DTMs undertake serious HR evaluation, 
and people analytics can be a crucial tool for the success of this process. However, DTMs are still new to this discipline, and many suffer from poor data quality, lack of skills, and a weak business case for change. Studies in people analytics have been undertaken, (Apgar, 2013: Cascio \& Boudreau, 2014: Angrave, et al., 2016), indicate that slow uptake and application of people analytics has however not been extensive and the new concept not yet benefitting the DTMs. Notably, there has not been much research information in the area especially in the Kenyan context. This study therefore aimed at adding knowledge on the influence of people analytics on the performance of deposit taking MFIs through the case of Nyeri County, Kenya.

\section{Objectives of the study}

The general objective of the study was to evaluate the effect of people analytics on the performance of deposit taking MFIs in Nyeri County, Kenya.

The guiding specific objectives were:

i. To determine the effect of human resource data access and the performance of MFIs in Nyeri County, Kenya.

ii. To determine the effect of data management capacity and the performance of MFIs in Nyeri County, Kenya.

iii. To establish the effect of stewardship and the performance of MFIs in Nyeri County, Kenya.

\section{Theoretical Review}

According to Douglas and King (2002), theories have been formulated and used to explain, predict, and understand phenomena and, in many cases, to challenge and extend existing knowledge within the limits of critical bounding assumptions. The following theories are adopted in this study to aid in conceptualization of study variables.

\subsection{The Diffusion of Innovation Theory (DOI)}

Diffusion of Innovation (DOI) Theory, developed by Rogers Everett in (1962), is one of the oldest social science theories. It originated in communication to explain how, over time, an idea or product gains momentum and diffuses (or spreads) through a specific population or social system. The concept is that every market has groups of customers who differ in their readiness and willingness to adopt a new product and that an innovative product spreads (diffuses) through a market not in one straight course but in successive, overlapping waves (Bharati \& Chaudhury, 2006). HR analytics represents a new innovation, even though it has been discussed for many years. Thus, treating HR analytics as a diffusing innovation seems appropriate. Rogers (2003) conceives the decision to adopt an innovation (e.g. something new or a new idea) as a 5-step process: knowledge, persuasion, decision, implementation, and confirmation. Since HR Analytics is still relatively new, at the early adopters stage (e.g. less than $20 \%$ of organizations), the study focuses on the questions relating to the first two stages: gaining knowledge about HR analytics and being persuaded about whether to adopt HR Analytics.

Individuals are seen as possessing different degrees of willingness to adopt innovations and thus it is generally observed that the portion of the population adopting an innovation is approximately normally distributed over time (Rogers, 1996). According to Bharati and Chaudhury (2006), there are five established adopter categories, and while the majority of the general population tends to fall in the middle categories, it is still necessary to understand the characteristics of the target population: Innovators; Early Adopters Early Majority; Late 
Majority and Laggards. The stages by which a person adopts an innovation, and whereby diffusion is accomplished, include awareness of the need for an innovation, decision to adopt (or reject) the innovation, initial use of the innovation to test it, and continued use of the innovation. The diffusion innovation theory as proposed by (Rogers, 2003) was adopted in this study as a basis for deriving the predetermined questions that guide evidence-based integrative synthesis technology adoption in people analytics.

\subsection{Resource Based View (RBV)}

The Resource-Based View, proposed by Wernerfelt (1984), focuses on developing internal value producing and unique capabilities and resources. The resource-based view as a basis for the competitive advantage of a firm lies primarily in the application of a bundle of valuable tangible or intangible resources at the firm's disposal (Wernerfelt, 1984). To transform a short-run competitive advantage into a sustained competitive advantage requires that these resources are heterogeneous in nature (Peteraf, 1993). Effectively, this translates into valuable resources that are neither perfectly imitable nor substitutable without great effort (Barney, 2001). In addition, through a consistent and sophisticated bundling of activities, their mutual reinforcement can help to further differentiate individual capabilities. Grant (1996) posits that the resource-based view (RBV) of the firm has influenced the field of Strategic Human Resource Management (SHRM) in a number of ways. This paper explores the impact of the RBV on the theoretical and empirical development of SHRM. It explores how the fields of strategy and SHRM are beginning to converge around a number of issues, and proposes a number of implications of this convergence. Information about employees from the various functions and departments in the organization can create a data base on which people analytics can be embedded. With the quest to achieve organizational goals, the contribution of the human resource is crucial and their competencies indispensable. In this study, the focus is on the human resource as a factor of production and determinant to organizational performance. The analysis of competencies of the workforce provide a strategic focus on HR decision making in regards to workforce productivity, hence making the theory applicable in formulating constructs for data application capacities for people analytics among managers and staff in the MFIs.

\subsection{Contingency Theory}

Fred Fiedler is a theorist whose Contingency Trait Theory was the precursor to his Contingency Management Theory. Fiedler believed there was a direct correlation to the traits of a leader and the effectiveness of a leader. According to Fiedler (1964), certain leadership traits helped in a certain crisis and so the leadership would need to change given the new set of circumstances. Fiedler's Contingency Theory says that there are many internal and external factors that can influence the optimum organizational structure. These factors include the size of the organization, technology that is in use, leadership style, and how the organization can adapt to changes in strategy (Jeong \& Nawi, 2012). Douglas and King (2002) posit that the contingency approach is a management theory that suggests the most appropriate style of management is dependent on the context of the situation and that adopting a single, rigid style is inefficient in the long term. Contingency managers typically pay attention to both the situation and their own styles and make efforts to ensure both interact efficiently. Huang (2001) suggests that contingency theory is beneficial to organizations because of the potential for learning from specific situations and using these lessons to influence future management of the same or similar situations. The ability to adapt to external pressures and changes is also an advantage. Contingency theory may also produce more well-rounded leaders who are able to develop their skills in multiple areas. 
HR competencies do not develop autonomously. HRM has become important because of the globalization, which stems from factors of the business environment. The development of HR competencies was due to the needs of organizations and the streams of scientific research in those eras. Marsman (2011) suggests the existence of contingencies within the domain of HR competencies. Deriving her conclusions about the importance of the environment from research of Hayton, Cohen, Hume, Kaufman, and Taylor (2005) and Douglas and King (2002), she states that changes in business requirements should be necessary due to the environment. As HR competencies and business requirements should fit, (Marsman, 2011), I can conclude that the environment, or business context as Marsman (2011) describes, also influences HR competencies. Contingency scholars argued that HRM strategy would be more effective only when appropriately integrated with a specific organizational and environmental context (Chang, \& Huang 2005). Accordingly, the organizations that closely coordinate their business strategy and HRM strategy achieve better performance outcomes in comparison to organizations that do not (Huang, 2001). Irrespective of the strategic framework being used (Lee \& Wu, 2010) the scientists propose three or four competitive strategies available to organization and an appropriate HRM strategy for each competitive strategy. Through Human Capital Management (HCM) software, and HR Analytics organizations can focus human capital with enhancing organization performance and this combination allows managers to both align incentives and monitor employee behaviour. The theory is significant in the conceptualization of stewardship in people analytics and its effect on the performance of MFIs.

\subsection{HRM Ability Motivation and Opportunity (AMO) Theory}

The AMO theory suggests that there are three independent work system components that shape employee characteristics and contribute to the success of the organization. According to the theory, organizational interests are best served by a system that attends to the employees Ability, Motivation, and Opportunity (AMO). Work performance depends on the ability, motivation and opportunity for employees in order to make their contribution and maintain their well-being. If just one of the factors is zero, then the total equation is zero, (Evanschitzky, Eisend, Calantone \& Jiang, 2012). Jackson, Renwick, Jabbour and MullerCamen (2011) contend that to increase AMO, leaders can use the three factors as a structure of appraisal interviews by comparing your employee responses to your own perception of what they can, desire and have the opportunity for in order to gain a mutual understanding. In order to create well-functioning teams, it is crucial that managers look inwards and assess the composition of their employee profiles. The risk of a wrong team composition is solely that the management won't succeed in creating a culture of trust, which increases the risk of disenabling necessary synergies between Ability, Motivation and Opportunity in overall team performance.

According to this theory, companies that hire individuals that have ability, and provide motivation and opportunity to perform their jobs well, will perform better than their rivals who do not have this combination (Delery \& Shaw, 2001). The AMO theory suggests that there are three independent work system components that shape employee characteristics and contribute to the success of the organization. According to the theory, organizational interests are best served by a system that attends to the employees' ability, motivation, and opportunity. Companies can utilize the AMO theory to provide organizational leaders with a management tool that can impact performance; (Jiang et al., 2012). If any one of the three characteristics is missing, performance is likely to be inhibited, but if all three are present, then performance is likely to be enhanced. High employee performance is a strong factor that contributes to organizational success. In improving the HR capacity to strategize on motivation for higher outputs, the AMO theory becomes handy for HR managers, thus 
enhancing conceptualization of the application of people analytics systems and its effect on employees work outputs and overall performance in MFIs.

\section{Empirical Literature}

Empirical research is based on observed and measured phenomena and derives knowledge from actual experience rather than from theory or belief. It entails the review of data collected appertaining to a particular research. It engages the most recent research available and aids in ascertainment of research gaps that a current study is to fill.

\subsection{HR data Access and Performance of MFIs}

Not all companies are data driven and not all companies fully comprehend the benefits of analytics. Needless to say, that as a consequence, not all companies fully understand what Big Data Analytics is about. Pape (2016) posits that data quality is often a problem when it comes to the people side of the business. HR teams must enlist the support of IT early to help build a program to clean up, rationalize, and continuously monitor data quality. Quantifying employee productivity is usually a rather qualitative, subjective exercise. But apparently, someone's electronic calendar and email behavior can speak volumes about his or her impact across an organization. Falleta (2014) conducted a survey to determine use of HR Analytics across Fortune 1000 firms. With a sample of 220 firms, Falleta (2014) reported that only 15\% of respondents claimed HR Analytics played a central role in determining or implementing HR strategy. Furthermore, HR Analytics primarily consisted only of analysing employee survey data. Lawler and Boudreau (2015) report the results of a survey of over 100 Fortune 500 companies suggesting less than a third of these companies have HR Analytics that measures the relationship between HRM processes and people and business impact. This ratio is low particularly considering that the survey shows that over $70 \%$ use HR metrics to establish how efficient their HR processes are.

Soundararajan and Singh (2016) undertook a study on leveraging data for competitive advantage in India. The study established that when adopting predictive analytics, many organizations make the mistake of oversimplifying the process by running bivariate correlations on a handful of HRIS data fields, often focusing on a single data source, or performing simple psychometric assessments. Unless the organization adopts a more complete stance by gathering data from different sources, internal or external, and then validate their model predictions against actual results, the credibility and value delivered by these models will remain questionable. Beatty (2015) posited that as HR managers are involved in many strategic and functional tasks, proper utilization of time can be challenging for them. Lack of availability of employee data - such as employee capabilities, training, background, interests and experience leads managers to put square pegs in round holesleading to frustration, lost time and opportunities. Improper time management affects performance and work relationships. Application of automated manager service tools (like people analytics) can be helpful to access employee data, make informed decisions, and manage team effectively.

\subsection{Data Management Capacity and Performance of MFIs.}

The value of information as an organisational asset is a concept that is gradually emerging in African institutions through the deployment of business intelligence/analytic solutions. However, whilst these tools are available, the complementary human resources competencies in the form of managers working with information, business analysts with statistical analysis, and organisational data management policies guarding data quality assurance, data/information security, among others, are scarce, (Angrave et al., 2016). Analyses are only as good as the data fed into tools and software. Working with consistent, timely, and accurate 
data is foundational to all analytics practices. Companies should educate HR's stakeholders and implement data governance programs to clean and maintain data accuracy and consistency across HR and operational data stores, (Kassim and Nagy, 2015). Deloitte (2015) reports that many organizations are also new to this discipline, and many suffer from poor data quality, lack of skills, and a weak business case for change". Firms may attempt to fill this capability gap by buying expensive solutions offered by external vendors. However, HR professionals generally agree that such capabilities are best built and developed internally. Despite this widespread view, knowledge about how such in-house development should take place is lacking.

Aral, Bryjolfsson and $\mathrm{Wu}$ (2012) demonstrated empirically that companies with HR Analytics but without Human Capital Management (HCM) software showed no performance effects. Other studies indicate, however, that information technology (IT) can be both an enormous enabler and a significant impediment to HR Analytics. As an enabler, conceptually HRM IT/e-HRM should capture, store and make accessible data from across company functions and produce reports, dashboard, and scorecards. The reality of current HRM- IT capabilities, however, does not match the promise. Cascio and Boudreau (2014) noted that most HR departments are sitting on mountains of data about their employees including demographic data, performance data, job history, compensation, and training. Until recently, this data has yet to be effectively and strategically leveraged by organizations. Bassi (2011) predicts that in the absence of necessary IT acumen (how to use analytic software tools) and financial skills (how to access and use measures of business results), HR functions will inevitably cede responsibility for analytics to both the IT and finance functions. Angrave et al. (2016) echo this concern and raise another problem that if HR is not fully involved in the modelling process, there is significantly greater scope for models to be constructed in a way which fundamentally misunderstands the nature of human capital inputs into the processes of production and service deliver.

It is not only the lack of analytical skill that appear to be impeding the uptake of HR Analytics within companies, there is a concern that should HR Analytics be adopted it will not be controlled by HR professionals but by others who may misinterpret or mis-specify the analyses. Rasmussen and Ulrich (2015) argue that in addition to a shortage of technical skills, recent evidence suggests that chief human resource officers with a clear business focus are also in short supply. The Global Human Capital Trends survey (2016) data show that HR is now more convinced of people analytics' importance than the business, with 82 percent of HR respondents viewing it as important or very important, compared to only 69 percent of business people viewing it as important or very important. HR has the opportunity to show the value and ROI that investment in analytics can bring, which will result in a willingness to invest further and spur acceleration in analytics capabilities. Actually, all this leads back to greater investment in HR, generating a virtuous cycle where higher ROI justifies greater analytics investment, (Mortensen et al., 2015). The promise of people analytics is linking this people data with different types of business data to create outcomes aligned with company goals such as increased revenues and lowered costs.

\subsection{Stewardship and Performance of MFIs}

Leadership and good staff management skills are essential to provide employees with what they need to be successful. HRM systems and tools can provide a good structure but will not guarantee success. The leadership of an organization can truly decide to treat people however they want to but they don't get to decide if people come or go as a consequence - the people decide this, (Thomas et al., 2010). The people also decide the level of creativity and effort they are willing to exert on behalf of an organization. According to Boudreau and Lawler 
(2015), leading-edge organizations are building analytics teams and adopting more sophisticated analytics tools in an effort to enhance their competitive advantage and attract and retain top talent in increasingly talent-constrained industries. They are using their data to analyze flight risk, identify characteristics of high-performing sales and service teams, predict compliance risks, assess engagement and culture, and identify leadership candidates. The best organizations are seizing upon collective data that can provide unique human-capital insights and enable managers to make better decisions about talent.

Effective staff management hinges on each manager's ability to provide leadership and relate to staff, (Campero, 2016). Ultimately, the responsibility for Human Resource Management activities rests with each manager. If a manager does not accept this responsibility, then HRM activities will only get partially done. Maximizing the potential of the human resources available within the MFI is directly dependent on a manager's skills and abilities to manage staff. In his study, Bersin (2015) opined that MFI's leadership, including the board and senior management must fully endorse HRM functions. This includes not only verbally supporting HRM initiatives, but more importantly, actively modelling the systems and tools including use of big data for people analytics. It is with this support that HRM will have an opportunity to impact the success and growth of the MFI. Wayne and Boudreau (2014) emphasize that HR analytics is being hampered by a lack of understanding of analytical thinking by the HR profession. This problem is compounded by the HR analytics industry, which is largely based on products and services, which too often fail to provide the tools for HR to create and capture the strategic value of HR data. Parry and Tyson. (2011) argue that there is a risk that analytics will further embed finance and engineering perspectives on people management at boardroom level in ways that will restrict the strategic influence of the HR profession. It may also damage the quality of working life and employee wellbeing, without delivering sustainable competitive advantage to the organizations that adopt it.

\subsection{HR Analytics and Performance}

The new digital age is increasingly transforming performance management in the workplace, supporting more frequent contextual and transparent feedback to employees. The idea of abolishing the annual performance review has been discussed, adopted, reversed, reinstated and modified many times across thousands of organizations over the past 50 or more years, and continues to make the news today (Yusuf, 2018). Despite all this, the performance review isn't going away anytime soon. Barriers to the success of microfinance institutions in developing countries that relate scalability, sustainability, outreach and the impact of various microfinance initiatives can be overcome through the adoption of innovative strategies to maximize outreach and sustainability (Dary, 2013). Innovation therefore gives a provision for easy access to accurate activities such as disbursements, repayments, deposits, withdrawals and money transfer thus making their completion faster and better controlled with minimal room for errors. He further states that there is no set format related to the set of indicators of innovation within the microfinance industry. Innovation therefore can be measured using either an input approach or output approach whereby the input approach looks at activities within the firm that stimulate or induce innovation such as research and development investments, level of education of the staff, level of experience of the staff among others.

Josh (2016) posited that regardless of underlying drivers, the Performance Management System in digital HR is being re-evaluated at each of its component parts, as organizations seek new ways to improve employee alignment, performance and engagement. Going by this trend, annual performance reviews will be replaced by frequent feedback and coaching which means that leaders will be held accountable for employees' career collaboration, particularly through new agile performance management practices. There will be increased feedback 
frequency from employees to meet the demand for more frequent feedback, which will force organizations to rethink what employee performance metrics are set and how they are communicated. Trevor, Amir, Tara and Tiffany (2016) contend that for many organizations, this would represent a significant change in culture, exposing accomplishments, actions and other aspects of performance beyond the silo of the employee-manger relationship. The good news is that performance management is coming back to life through advanced digital technologies that are revolutionizing workplace management. One trend driving a more personalized approach to performance management is the speed at which the business and technology environment is changing. Technology enabled performance management is far more comprehensive and holistic. It focused on maximizing people development, improving the performance of individuals and the entire organization. Deloitte (2017) Global Human Resource Trend analysis report indicates that data about people at work has become more important than ever, but the focus of people analytics has changed. Formerly a technical discipline owned by data specialists, people analytics is now a business discipline, supporting everything from operations and management to talent acquisition and financial performance (Deloitte, 2018). Christie and Stephanie (2016) earlier noted that readiness to capitalize on people analytics remains a challenge, however. Only 8 percent of organizations report they have usable data, while only 9 percent believe they have a good understanding of the talent factors that drive performance. However, there is limited information on the uptake and effect of people analytics on the performance of DTMs in Kenya.

\section{Conceptual Framework}

The main role of the conceptual framework is to present the relationship between the independent and dependent variables. An independent variable is the presumed cause of changes in the dependent variable (Kothari, 2004). The dependent variable in this study is organizational performance while the independent variables will be: technology adoption, HR data access, data management capacity and stewardship. The conceptual framework in Figure 1 is based on the objectives of the study and the empirical literature review of the independent and dependent variables.

\section{Independent Variables}

People Analytics

\section{HR data Access \\ - Data availability \\ - Data Reliability \\ - Automated manager service tools}

\section{Dependent Variable}

\section{Organizational Performance}

Organizational Performance

- Efficiency in Operations

- Customer loyalty

- Growth

Figure 1 Conceptual Framework 


\section{Research Methodology}

Descriptive research design was used in preliminary and exploratory studies to allow the researcher gather information, summarize, present and interpret it for the purpose of clarification. Being a social study, the descriptive design was found appropriate as respondents were expected to explain the aspects of people analytics and DTMs performance as they perceive. The study population was 173 respondents composing, human resource managers, Sales and Marketing Supervisors, Finance officers, as well as staff in the human resource and ICT department from 8 registered deposit taking micro-finance institutions in Nyeri. The targeted population was expected to compose key informants on the study subject. Stratified sampling method was employed in sampling all the staff in the 8 DTMs. This method of sampling is useful when subgroups of the population vary dramatically in size such as the case of SMEs. The HR managers were all (8) considered for data collection. Stratification was applied at the rate of $30 \%$ on the 173 targeted persons to achieve the sample size of fifty-four (58) respondents. According to Saunders, Lewis and Thornhill (2009), a sample size of over $10 \%$ may be deemed representative of the universe. A questionnaire was adopted in this study which was semi structured questionnaire. Mugenda (2003) indicates that questionnaires include a series of precise, normally short questions which are answered by the respondent on their own or asked either verbally by an interviewer. The questionnaires were administered using drop and pick method, hence the researcher dropped them to the respondent, gave them time to complete, and then the researcher picked the questionnaire at a later date. The researcher contacted the leaders of the organizations and arrange for meetings with the relevant employees to get authority for respondents' access. A research assistant was engaged in dropping and picking the questionnaires and provided guidance without leading respondents to answer the questions.

The quantitative data obtained from the instrument was analyzed adequately using both descriptive and inferential statistics respectively with the help of SPSS and excel computer software for analysis of content on percentage, charts and means and other graphs for actual representation. Coding of data was done after checking for completeness and consistency. This enabled grouping of responses into different categories. Descriptive statistics summarized the sample and the observations through charts and tables whereas inferential statistics looks for potential relations between variables after examination of the set of data. Questions that were to be answered in the research were examined and conclusions drawn about the population using the sample. Correlation and regression coefficients analysis was adopted to find out the relationship between the independent and the dependent variables to answer the questions in the study. The study hypothesis was that people analytics does not affect the performance of MFIs in Nyeri County. Regression analysis was carried out as the significant effects of independent variables $\left(X_{1}, X_{2}, X_{3}\right)$ on dependent variable (Organizational Performance of DTMs). Tests of significance at $95 \%$ confidence level shall be applied on quantitative findings to establish the significance influence of each independent variable on the organizational performance of DTMs. Analysis variance (ANOVA) was used to determine the relationship of the variables. Regression analysis was used to come up with the model expressing the hypothesized relationship between the independent variables (technology adoption, human resource data access, data management capacity and stewardship) and the dependent variable (organizational performance of deposit taking microfinance institutions in Nyeri County, Kenya). Data was interpreted through adjusted $\mathrm{R}^{2}$ and $\mathrm{p}$ values at $95 \%$ confidence level. 


\section{Data Analysis Results}

Upon descriptive data analysis, the study undertook inferential statistics to establish the relationship between the variables. Karl Persons Correlation analysis was applied to test the relationship between the independent variables; with the confidence level $(95 \%, 0.05)$ was used to establish the significance of the relationships. The results are as stipulated in table 1 below.

Table 1 Correlation Analysis

\section{Performance}

\begin{tabular}{llc} 
HR Data Access & Pearsons & $.680^{* *}$ \\
& Sig. & .013 \\
Data Management & $\mathbf{N}$ & $\mathbf{5 2}$ \\
& Pearsons & $.584^{* *}$ \\
& Sig. & .022 \\
Stewardship & $\mathbf{N}$ & $\mathbf{5 2}$ \\
& Pearsons & $.584^{* *}$ \\
& Sig. & .214 \\
& $\mathbf{N}$ & $\mathbf{5 2}$ \\
\hline
\end{tabular}

\section{Source: Researcher (2019)}

Results in table 1 above show the significant between the variables. It is evident that there were positive relations between the study's three independent variables (Technology Adoption .021<.05; HR data access.013<.05; and Data Management.022<.05, though stewardship showed no significant relationship $(.214>.05)$. Thus, technology adoption was crucial for effective data access and management, critical aspects of the implementation of people analytics. Regressions analysis was thereafter applied to test the study's focused on whether there was a relationship between the independent and dependent variables. The study applied ordinal regression in testing the relationship between people analytics and performance of DTMFIs in Nyeri County. The ordinal regression was used because all the variables were categorical variables. Results shall be presented herein after. To start with, thorough screening of data was conducted through diagnostic tests in ensuring data sets met the general assumptions for conducting the regression analysis, a key analytical model that the study must develop.

The regression implication of independent variables was sough and results were as stipulated in table 2 and 3 below.

\section{Table 2 Model Fit Results}

\section{Model Fitting Information}

\begin{tabular}{lrrrr} 
Model & -4 Log Likelihood & Chi-Square & F & Sig. \\
Intercept Only & 132.231 & & & \\
Final & 86.841 & 44.277 & 11 & 0.0401 \\
\hline
\end{tabular}

\section{Source: Researcher (2019)}

The results show that the independent variables were significant $(0.041)$ in the study. Further tests were conducted and the summary of fitness model stipulated in table 4.11 below. 
Table 3 Model Summary of Independent Variables

\section{Pseudo R-Square}

Cox and Snell

0.512

Nagelkerke

0.548

McFadden

0.216

\section{Source: Researcher (2019)}

The model shows four different results for the $\mathrm{R}^{2}$ as is the case on ordinal regression outputs. In the selection of $\mathrm{R}^{2}$ value the researcher's judgment was critical based on the correlation to select $\mathrm{R}^{2}$ value for the model. Due to three independent values being significant, the researcher selected 0.512 as the $\mathrm{R}^{2}$ value for the model (Table 4.10). The model shows $\mathrm{R}$ square of 0.512 meaning $51.2 \%$ of the outcome was predicted by the independent variables. This means that the model cannot explain $48.8 \%$ of the remainder. Therefore, guided by Seber \& Lee (2012), it was concluded that at least one of the variables under assessment were useful predictors of financial performance.

The current study sought to establish the relationship between people analytics and performance of MFIs. ANOVA was used to test the significant relationship between people analytics aspects and performance of MFIs

Table 4 ANOVA Test Results

\begin{tabular}{|c|c|c|c|c|c|c|}
\hline \multicolumn{3}{|c|}{ ANOVA $^{\mathrm{a}}$} & \multirow[b]{2}{*}{ of Df } & \multirow[b]{2}{*}{$\begin{array}{l}\text { Mean } \\
\text { Square }\end{array}$} & \multirow[b]{2}{*}{$\mathbf{I}$} & \multirow[b]{2}{*}{ Sig. } \\
\hline Model & 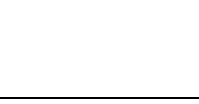 & $\begin{array}{l}\text { Sum } \\
\text { Squares }\end{array}$ & & & & \\
\hline \multirow{3}{*}{1} & Regression & 66.381 & 11 & 5.595 & 7.67 & $.000^{\mathrm{b}}$ \\
\hline & Residual & 244.739 & 255 & .825 & & \\
\hline & Total & 333.121 & 57 & & & \\
\hline
\end{tabular}

a. Dependent Variable: Performance

b. Predictors: (Constant), Technology Adoption, HR Data Access, Data Management, Stewardship

\section{Source: Researcher (2019)}

The results of ANOVA revealed that the entire model was significant with the $\mathrm{F}$ ratio $=7.67$ at $\mathrm{p}$ value $0.000<0.05$. This is an indication that the model can be relied upon, with $76.7 \%$ effect on MFIs performance being caused by the independent variables, and $23.3 \%$ effect contributed by other factors not considered in this study.

\section{Regression Coefficients}

Table 5 Coefficients of the regression model

\begin{tabular}{|c|c|c|c|c|c|}
\hline Parameter Estimates & \multicolumn{2}{|c|}{ Estimate $(\beta)$} & Std. Error & Wald Df & Sig. \\
\hline (Constant) & .663 & 1.215 & & -.546 & .587 \\
\hline HR Data Access & .445 & .096 & .474 & 4.620 & .009 \\
\hline Data Management & .351 & .141 & .274 & 2.489 & .015 \\
\hline Stewardship & .394 & .107 & .410 & 3.675 & .011 \\
\hline
\end{tabular}

Source: Researcher (2019) 
The coefficients analysis gives $\beta_{0}$ (Beta) at $0.663, \beta_{1}$ at $0.21, \beta_{2}$ at $0.445, \beta_{3}$ at 0.351 and $\beta_{4}$ at 0.394 (Table 4.11). Where $\beta_{0}$ is the constant, $\beta_{1}, \beta_{2}$ and $\beta_{3}$ are parameter for estimation of the independent variables; technology adoption, HR data access, data management and stewardship towards people analytics implementation. The study hypothesis was that people analytics does not affect the performance of MFIs in Nyeri County, forming the regression equation; $Y=\beta_{0}+\beta_{1} X_{1}+\beta_{2} X_{2}+\beta_{3} X_{3}+\beta_{4} X_{4}$. Where performance of the MFIs (Y); influencing factors measured include technology adoption, HR data access, data management and stewardship, and are denoted by $\mathrm{X}_{1}, \mathrm{X}_{2} \mathrm{X}_{3} \mathrm{X}_{4}$. It is evident from the above regression model that if all factors were to be held constant including technology adoption, HR data access, data management and stewardship, changes in MFIs performance would be at 0.663 of a unit. There was a positive significant effect between the independent and dependent variable and as such: a unit change in technology adoption would lead to .21 change in performance of MFIs. A unit change in HR data access would lead to .445 change in performance of MFIs, while a unit change in data management would lead to.351 change in performance of MFIs, and a unit change in stewardship would lead to .394 changes in performance of MFIs. The regression equation of the model becomes: $\mathrm{Y}=$ $0.663+0.445 \mathrm{X}_{2}+0.351 \mathrm{X}_{3}+0.394 \mathrm{X}_{4}+\varepsilon$.

Correlation between the variables was undertaken at 95\% confidence level (sig., .05). The coefficient of the regression for technology adoption was sig 0.911>.05, indicating an insignificant effect on performance of MFIs. The resultant coefficients for the other three independent variables showed a significant relationship with dependent variable: HR data access (sig $0.009<.05$ ), data management (sig 0.015<.05) and stewardship (sig $0.011<.05$ ). Thus, the three variables of people analytics significantly influenced the performance of Micro Finance Institutions in Nyeri County. In concurrence with the findings, Sparrow, Hird and Cooper (2015) posited that people analytics has the ability to challenge conventional wisdom, influence behavior, enable talent and business leaders to make and execute smarter and more strategic workforce decisions, and ultimately impact business outcomes. The significant between technology adoption and performance of MFIs was not significant. As observed, the MFIs had invested in technology infrastructure, thus not a critical hindrance to the application of people analytics and impact on performance of the firms. Jones (2014) underscored that Technology providers are embedding applications with functionality to move beyond reporting and actually providing the groundwork for data-driven discussion. Thus, since technology had been embraced by the MFIs it did not hinder development of human resource for higher output and overall performance of the MFIs.

\section{Conclusion}

The study evaluated the effect of people analytics on the performance of MFIs. People analytics was cited as the application of technology and science in analyzing the skills and performance of individual and teams working in firms. The study found that ICT infrastructure was well developed in the MFIs, though people analytics apps were lowly developed. However, technology adoption was not found to significantly affect the performance of MFIs in Nyeri County. There was found to be a significant effect between access to HR data access and the performance of MFIs in Nyeri County. Data management had an effect on people analytics operationalization, with critical challenges on the human resource, rather than technology itself. Stewardship of the managers in implementation of people analytics was also found to affect performance, since low competence of managers have led to poor analysis of staff capacities and causing frictions, dismantling team work and thus operations of the firm. Significant relationship between stewardship and the performance of MFIs in Nyeri County. Respondents' suggestions for the improvement of people analytics influence on the performance of the firm geared mostly on capacity development, as well as 
research and development. Outsources of people analytics, regarded a non-core function was also suggested. This study concludes that having invested in ICT, technology adoption did not significantly affect people analytics implementation. However, HR data access, data management and stewardship aspects of people analytics had significant effect on the performance of Microfinance Institutions.

\section{Recommendations}

This study recommends that first; to enhance technology diffusion, MFIs HR managers must invest in people analytics support systems; new apps that are platforms for people analytics including cloud computing and artificial intelligence. The apps are able to enhance data access, management, mining and analysis to provide a more accurate data of the staff, department and the organization as a whole. To improve quality of data and accessibility, MFIs should collaborate with social media platforms to enable access to social networks of the staff. The firms could outsource information access services to reduce possible tensions with the staff. Importantly, it should inform the staff of such undertaking to avoid infringement of the right to privacy. In regards to data management and usage, the firms need to re-evaluate the techniques for staff analysis. Modern technology has presented more efficient and scientific methods of capacity evaluation of the workforce. They should invest in research and development and figure-out how and whether this technology can enhance their staff appraisal capacities. Training is critical for capacity development. It is recommended that the MFIs managers should formulate training programmes for management and other staff to create awareness and enable acceptance of the techniques, and as such reduce tensions between managers and staff. Importantly, training managers shall enhance stewardship in the workplace, delegation of the right concepts, preparation of concrete analytical results and reports. The study found that people analytics can enhance the performance of a firm. It is therefore important that the MFIs organize capacity building programmes for managers and directors who may be able to provide stewardship in people analytics implementation, train the staff on its use and benefits.

\section{References}

Angrave, D., Charlwood, A., Kirkpatrick, I., Lawrence, M., \& Stuart, M. (2016). HR and analytics: why HR is set to fail the big data challenge. Human Resource Management Journal, 26: 1-11.

Apgar, D. (2013). The false promise of big data: Can data mining replace hypothesis-driven learning in the identification of predictive performance metrics? Systems Research and Behavioural Science. Online first publication, doi: 10.1002/sres.2219.

Aral, S., Bryjolfsson, E. and Wu, L (2012). 'Three-way complementarities: Performance Pay, Human Resource Analytics, and Information Technology'. Management Science, 58(5): $913-931$.

Ashraf, Nava, Oriana Bandiera, and B. Kelsey Jack (2014): "No Margin, No Mission? A Field Experiment on Incentives for Public Services Delivery." Journal of Public Economics 120: 1-17.

Bharati, P., \& Chaudhury, A., (2006)"Current Status of Technology Adoption: Micro, Small and Medium Manufacturing Firmsin Boston". Management Science and Information Systems Faculty Publication Series. Paper 13

Bharati, P. and Chaudhury, A. (2006), "Current Status of Technology Adoption: Micro, Small and Medium Manufacturing Firms in Boston", Communications of the ACM,

Barney J.B. (2001). "Is the Resource-Based Theory a Useful Perspective for Strategic Management Research? Yes". Academy of Management Review. 26 (1): 41-56. 
Ben D. (2013): “The Bias Undermining Your People Analytics.” Harvard Business Review Article, December 19.

Berkeley D., Joseph S. and Cade M., (2015) "Algorithm Aversion: People Erroneously Avoid Algorithms After Seeing Them Err.” Journal of Experimental Psychology 144: 114 126.

Bennett, C., \& Collins, L., (2015) HR and people analytics Stuck in neutral. Global Human Capital Trends (2015), leading in the new world of work. Deloitte University Press.

Bersin J (2015). 'Why people management is replacing talent management.' Joshbersin.com downloaded from http://joshbersin.com/2015/01/why-people-management-is-replacingtalent-management/\#disqus_thread on 10/11/2017.

Boston Consulting Group. (2014). Creating people advantage 2014-2015. Boston, MA: The Boston Consulting Group, Inc.

Boudreau, J. and Lawler, E. (2015). Making Talent Analytics and Reporting into a Decision Science. Working paper, Centre for Effective Organizations. University of Southern California.

CAHRS (2014). CAHRS Working Group on HR analytics summary report part 1. Ithaca NY: Cornell University Centre for Advances Human Resources (downloaded from http://cahrs.ilr.cornell.edu/CentersofExcellence/data.aspx?n=HR\%20Analytics/Metrics \#Research on 31/10/2014).

Campero, S., (2016): "Does Firm Status Confer a Recruiting Advantage? Evidence from High-Tech Entrepreneurial Firms" MIT Sloan School of Management Working Paper.

Cascio, W. and Boudreau, J. (2014). Investing in People: The Financial Impact of Human Resources Initiatives ( $2^{\text {nd }}$ Edition). Upper Saddle NJ: Pearson Press.

Chiang, Y. H., Shih, H. A., \& Hsu, C. C. (2014). High commitment work system, transactive memory system, and new product performance. Journal of Business Research, 67, 631640.

Chartered Institute of Personnel and Development CIPD (2013). Talent Analytics and big data - the challenge for HR. London: Chartered Institute for Personnel and Development.

Christie S., \& Stephanie T., (2016), The Millennial majority is transforming your culture, Deloitte, pp. 1-15,

Coco, C. T., Jamison, F., \& Black, H. (2011). Connecting people investments and business outcomes at Lowe's: Using value linkage analytics to link employee engagement to business performance. People \& Strategy, 34, 28-33.

Dauda, Y.A., Akingbade, W.A., \& Akinlabi, H.B. (2010). Strategic human resource management practice and corporate performance of Small Business Enterprises in Lagos Metropoli International Journal of Business Management, 5(11), 97-105

Deloitte (2018) Rewriting the rules for the digital age 2017. Deloitte Global Human Capital Trends

Dary, S. K. (2013). Exploring Innovations in Microfinance Institutions in Northern Ghana.

Douthit, S. and Mondore, S. (2014). 'Creating a business-focused HR function with analytics and integrated talent management'. People and Strategy, 36:4, 16 - 21.

Evans, P. Pucik, V. Björkman, I. (2011). The Global Challenge - International Human Resource Management. 2nd ed. New York: McGraw-Hill. ch3.

Evanschitzky, H., M. Eisend, R.J. Calantone and Y. Jiang, (2012). Success factors of product innovation: An updated meta-analysis. J. Prod. Innov. Manage., 29: 21-37.

Falletta, S. (2014) In search of HR intelligence: evidence-based HR analytics practices in high-performing companies. People and Strategy. Vol 36. Pp 28-37.

Fecheyr-Lippens, B., Schaninger, B. \& Tanner, K. (2015). Power to the new people analytics. McKinsey Quarterly, 51(1): 61-63. 
Fiedler, F. E. (1964). A theory of leadership effectiveness. In L. Berkowitz (Ed.), Advances in experimental social psychology. New York: Academic Press.

Fink, A. (2010). 'New trends in human capital research and analytics'. People and Strategy, $33: 2,15-21$.

Franklin, M.I. (2012). Understanding Research: Coping with the Quantitative-Qualitative Divide London and New York: Routledge.

George, G. Haas, M. and Pentland, A. (2014). 'Big data and management'. Academy of Management Journal, 57:2, 321 - 326.

Grant, R. M. (1996). Toward a knowledge-based theory of the firm. Strategic Management Journal, 17 (Winter Special Issue), 108-122

Huang, T-C. (2001). The effects of linkages between business and human resource management strategies. Personnel Review, 30 (2), 132-151.

Huselid, M. (2015). Workforce Analytics for Strategy Execution. In Ulrich, D., Schiemann, W., \& Sartain, L. (eds) The rise of HR: Wisdon from 73 thought leaders. HR Certification Institute, VA.

Hayton, J. C., Cohen, D., Hume, F., Kaufman, B., \& Taylor, J. (2005). Conversations on what the market wants from HR graduates, and how can we institutionalize innovation in teaching. Microfinance Insight. An Intellecap Publication

Jackson, S.E., D.W.S. Renwick, C.J.C. Jabbour and M. Muller-Camen, (2011). State-of-theart and future directions for green human resource management: Introduction to the special issue. Zeitschrift Fur Personalforschung, 25: 99-116.

Jeong, Chun Hai, Ibrahim, \& Nor Fadzlina, Nawi. (2012). Principles of Public Administration: Malaysian Perspectives. Kuala Lumpur: Pearson Publishers.

Josh B., (2016). HR technology disruptions for 2017: Nine trends reinventing the HR software market, Bersin by Deloitte.

Josh Bersin, (2014). The datafication of HR, Deloitte University Press,

Kassim, I. and Nagy, M. (2015). The State of Workforce analytics in Europe. Workforce Analytics Summit.

Katua, T., Mukulu, E., \& Gachunga, H. (2014). Effect of employee resourcing strategies on the performance of commercial banks in Kenya. International Journal of Education and Research, 2(1), 1-20.

Kothari, C.R. (2004). Research Methodology: Methods and Techniques. New Delhi: New Age International (P) Ltd.

Lan, L. and Heracleous, L. (2010), Rethinking Agency Theory: the View from Law', Academy of Management Review, 35, 2: 294-314

Laumer, S., Eckhardt, A. and Weitzel, T. (2010) Electronic Human Resources Management in an E-Business Environment. Journal of Electronic Commerce Research, 11, 240250.

Liao, Y-S. (2005). Business strategy and performance: the role of human resource management control. Personnel Review, 34 (3), 294-309.

Lee, F-H., Lee, T-Z., \& Wu, W-Y. (2010). The relationship between human resource management practices, business strategy and firm performance: evidence from steel industry in Taiwan. The international Journal of Human Resource Management, 21(9), 1351-1372.

Magala, J. (2010), Relationship lending in a competitive industry, Journal of management Vol 2, No 11pp 11.

Manyika, J. Chui, M. Brown, B. Bughin, J. Dobbs, R. Roxburgh, C. and Byers, A. (2011). Big data: The next frontier for innovation, competition and productivity. McKinsey \& Company. 
Margaret Schweer, Dimitris Assimakopoulos, Rob Cross, and R. Thomas (2012): “Building a Well-Networked Organization." Sloan Management Review, Winter.

Marsman, E. M. (2011). HRM Competences: old or new? Results of the qualitative exploration into business requirements. Enschede: Twente University.

Michael, S., David B., \& Robin E., (2017) "Talent acquisition: Enter the cognitive recruiter," Global Human Capital Trends 2017: Rewriting the rules for the digital age, Deloitte University Press

Mortensen, M. Doherty, N. and Robinson, S. (2015). Operational research from Taylorism to Terabytes: A research agenda for the analytics age. European Journal of Operational Research, 241: 583 - 595.

Mugenda, A.G. (2003). Applied Research and Training Services: Social Science. Nairobi

Muogbo, U.S. (2013). The impact of employee motivation on organisational performance (a study of some selected firms in Anambra state Nigeria). The international journal of engineering and science, 2(7), 70-80.

Orodho J.A. (2004) Techniques of Writing Research Proposals and Reports in Education, Masda Publishers

Pape, T. (2016). Prioritizing data items for business analytics: Framework and application to human resources. European Journal of Operational Research, 252, 687-698.

Parry, E. (2011). 'An examination of e-HRM as a means to increase the value of the HR function.' The International Journal of Human Resource Management, 22:5, 1146 1162.

Parry, E. and Tyson, S. (2011). Desired goals and actual outcomes of e-HRM. Human Resource Management Journal, 21, 3: 335 - 354.

Pawson, R. and Tilley, N. (1997), Realistic Evaluation. London: Sage.

Peteraf M.A. (1993). "The Cornerstones of Competitive Advantage: A Resource-Based View". Strategic Management Journal. 14 (3): 179-191.

Rasmussen, T. \& Ulrich, D. (2015). How HR analytics avoids being a management fad. Organizational Dynamics, 44(3): 236-242

Rasmussen, T. and Ulrich, D. (2015). 'Learning from Practice: How HR analytics avoids becoming a fad.' Organizational Dynamics, online first publication. doi:10.1016/j.orgdyn.2015.05.008

Rogers, Everett M. (1962). Diffusion of innovations (1st ed.). New York: Free Press of Glencoe

Rodger, J. A., Pendharkar, P. C., \& Bhatt, G. D. (1996). Diffusion theory and the adoption of software innovation: Common errors and future issues. Journal of High Technology Management Research, 7(1), 1-13.

Saunders, M., Lewis, P., \& Thornhill, A. (2009).Research Methods for Business Students (5thed)Essex: Pearson Education.

Sekaran, U., \& Bougie, R., (2010). Research Methods for Business. A Skill Building Approach (5th ed.). Chichester West Sussex UK John Wiley and Sons

Silverman, D., (2011). Qualitative Research: Issues of Theory, Method and Practice, Third Edition. London, Thousand Oaks, New Delhi, Singapore: Sage Publications

Smeyers, L. (2015). What we learned about HR analytics in 2014 - part 2. Downloaded from http://www.inostix.com/blog/en/what-we-learned-about-hr-analytics-in-2014-part-2/on $4 / 5 / 2015$.

Soundararajan, R. \& Singh, K. (2016). Winning on HR Analytics: Leveraging Data for Competitive Advantage. India: Sage Publications.

Sparrow, P., Hird, M. and Cooper, C. (2015). Do we need HR? Repositioning people management for success. Basingstoke: Palgrave Macmillan. 
Sullivan, J., (2013) How Google Is Using People Analytics to Completely Reinvent HR. Talent Management and HR. Feb, 2013. TLNT.

Thomas H. D., Jeanne H., and Jeremy S., (2010): “Competing on Talent Analytics.” Harvard Business Review, October: 6pp.

Trevor P., Amir R., Tara M., \& Tiffany M., (2016). Unlocking the flexible organization: Organizational design for an uncertain future, Deloitte

Upadhaya, B., Munir, R., \& Blount, Y. (2014). Association between Performance Measurement Systems and Organisational Effectiveness. International Journal of Operations \& Production Management, 34(7), 2-2.

Van den Heuvel, S., \& Bondarouk, T. (2016). The rise (and fall) of HR Analytics: A study into the future application, value, structure, and system support. Paper presented the 2nd HR Division International Conference (HRIC), Sydney (AU).

Ulrich, D. and Dulebohn, J. (2015) Are We There Yet? What's Next for HR? Human Resource Management Review, 25: 188-204

Wayne C., \& Boudreau, J., M., (2014) "HR strategy: optimizing risks, optimizing rewards", Journal of Organizational Effectiveness: People and Performance, Vol. 1. pp.77 - 97

Wernerfelt B (1984). "The Resource-Based View of the Firm". Strategic Management Journal. 5 (2):171-180

Wolfe, R., Wright, P., \& Smart, D. (2006). Radical HRM innovation and competitive advantage: The Moneyball story. Human Resource Management, 45(1), 111-126.

Yusuf S. S., (2018) How HR can help universities to be ready in the new digital age. The Association of Commonwealth Universities. Canada

This is an open-access article published and distributed under the terms and conditions of the $(\mathrm{cc}) \mathrm{EY}$ Creative Commons Attribution 4.0 International License of United States unless otherwise stated. Access, citation and distribution of this article is allowed with full recognition of the authors and the source.

Authors seeking to publish with an International Peer Reviewed Journal should consider https://www.ijcab.org/ by writing to the Editor at editor@ijcab.org. The articles must be quality and meet originality test. 